University of Nebraska - Lincoln

DigitalCommons@University of Nebraska - Lincoln

\title{
Fracture analysis of Kevlar-49/epoxy and e-glass/epoxy doublers for reinforcement of cracked aluminum plates
}

Ananth Ram Mahanth Kasavajhala

University of Nebraska-Lincoln

Linxia Gu

University of Nebraska-Lincoln, gul@fit.edu

Follow this and additional works at: https://digitalcommons.unl.edu/mechengfacpub

Part of the Mechanical Engineering Commons

Kasavajhala, Ananth Ram Mahanth and Gu, Linxia, "Fracture analysis of Kevlar-49/epoxy and e-glass/ epoxy doublers for reinforcement of cracked aluminum plates" (2011). Mechanical \& Materials Engineering Faculty Publications. 45.

https://digitalcommons.unl.edu/mechengfacpub/45

This Article is brought to you for free and open access by the Mechanical \& Materials Engineering, Department of at DigitalCommons@University of Nebraska - Lincoln. It has been accepted for inclusion in Mechanical \& Materials Engineering Faculty Publications by an authorized administrator of DigitalCommons@University of Nebraska Lincoln. 


\title{
Fracture analysis of Kevlar-49/epoxy and e-glass/epoxy doublers for reinforcement of cracked aluminum plates
}

\author{
Ananth Ram Mahanth Kasavajhala and Linxia Gu \\ Department of Mechanical Engineering, University of Nebraska-Lincoln, Lincoln, NE 68588-0656, USA \\ Corresponding author - L. Gu, tel 402 472-7680, fax 402 472-1465, email lgu2@unl.edu
}

\begin{abstract}
Adhesively bonded composite patch repair is efficient means to regain load carrying capacity, alleviate the crack growth, and improve the service life of the damaged structure. In this paper, three dimensional finite element models are developed to examine the fracture behavior of a single edge V-notched Aluminum plate repaired with Kevlar-49/epoxy or e-glass/epoxy prepreg patches on both sides. Contour integral method was used for evaluating the stress intensity factor (SIF), an indicator of the crack stability. The load transfer mechanisms, stress distribution, damage variable $(D)$, and crack mouth opening displacement (CMOD), were also presented to estimate the effectiveness of composite patch repair. The influence of the patch material, crack length and the adhesive thickness has been investigated. Results have shown that the crack induced damage increased nonlinearly with a larger crack size. With the composite patch repairs, SIF is reduced to $1 / 7-1 / 10$ of that of the bare plate and CMOD decreased by $79 \%$. The damage variable is reduced significantly and the load capacity is increased. A thinner adhesive layer results in a higher percentage of load shared by the composite patch.
\end{abstract}

Keywords: Structural composites, Finite element analysis (FEA), Stress concentrations, Stress transfer, Damage variable

\section{Introduction}

Adhesively bonding composite patches on either single or double sides of a damaged structure also referred to as bonded composite repair, have been shown to be efficient in reducing the stress intensity at the crack tip and thus improving the service life of the damaged structure. Boned composite repair would develop complicated 3-D stresses even for a simple plate under in-plane loading condition. It is then challenging to derive stress intensity factors and predict the fatigue behavior of the repaired structure. Since the first use of a composite patch to repair damaged aircraft and marine structures [1], progresses have been made to improve the accuracy of prediction methods and the effectiveness of bonded composite patch repair technique [2-5]. Various numerical methods such as boundary element method, collocation method, finite difference method, finite element method and finite element alternating method have been developed for a better prediction of fracture. Finite element method gains popularity with the introduction of Quarter Point Elements at the crack tip [6, 7]. Several other element types were discussed to improve the accuracy of SIF estimation [8]. However, numerical models are usually simplified to avoid the high aspect ratio element and reduce the computational time $[9,10]$. In addition to the obvious high cost of computation, high aspect ratio elements are needed for the thin adhesive layer and patches, which usually cause convergence problems.
A two dimensional finite element code, utilizing plane stress elements to mimic the repaired plate, referred to as FRacture ANalysis Code for 2D Layered structure (FRANC2DL), is being used by many researchers [11-13]. However, 2D models cannot capture the out-of-plane deformation along the crack front which has considerable impact on the stress intensity factor across the plate thickness [14]. The use of three dimensional models to perform fracture analysis is lacking [10].

In this paper, three dimensional finite element models with high aspect ratio elements have been constructed for double sided composite repairs of Al7075-T6 Single Edge Notch Tension (SENT) specimen. Both Kevlar-49/epoxy and e-glass/epoxy are evaluated due to their high impact properties and low cost [15]. The influence of patch material, initial crack length, and the adhesive thickness were examined in terms of load transfer mechanism, stress distribution, SIF, COMD and damage variable $D$.

\section{Finite element model}

A three dimensional plate with a pre-existent V-notched crack, as shown in Figure 1, was investigated using commercial nonlinear finite element software ABAQUS (Dassault Systémes Simulia Corp., RI, USA). The structure has been meshed using second order hexahedral elements. The crack tip, due to the singularity caused by its sharp edges, was modeled as quar- 


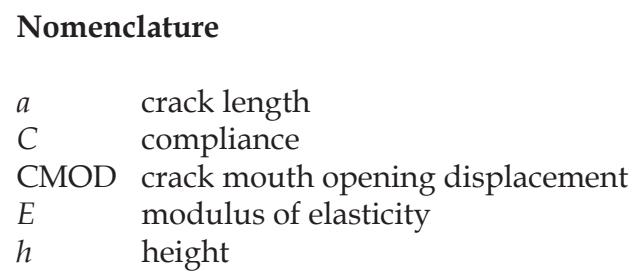

SENT single edge notch in tension

SIF stress intensity factor

$t \quad$ thickness

$w \quad$ width

$v \quad$ Poisson's ratio

$\sigma \quad$ applied nominal pressure or stress ter point elements, which transform from the 20-node brick elements by moving the midside nodes of the elements at the crack tip to quarter distances from the crack tip.

The plate is $305 \mathrm{~mm}$ in height, $51 \mathrm{~mm}$ in width, and $1.6 \mathrm{~mm}$ in thickness. The length of the crack is initially set as $8 \mathrm{~mm}$ with a crack mouth opening of $0.5 \mathrm{~mm}$. A rectangular patch and adhesive with the dimensions $h_{p}=h_{a}=117 \mathrm{~mm}$, $w_{p}=w_{a}=w=51 \mathrm{~mm}, t_{p}=0.66 \mathrm{~mm}$, and $t_{a}=0.12 \mathrm{~mm}$ has been used, where the adhesive and the patch are indicated as subscripts " $a$ " and " $p$ ", respectively.

The material properties for the Al7075-T6 plate, FM 73 adhesive, Kevlar-49/epoxy, and e-glass/epoxy pre-preg patches are summarized in Table 1 . The Al plate is subjected to a uniform linear ramping load of $250 \mathrm{MPa}$ on one end while the other end is fixed.

The crack front and its extension direction were defined using contour integral method, which uses domain integral technique to expand area integral in two dimensions and volume integral in three dimensions [16]. Furthermore this technique provides better accuracy if a focused mesh at the crack tip is used. The stress intensity factors $\left(K_{\mathrm{I}}, K_{\mathrm{II}} \& K_{\mathrm{III}}\right)$ and J-integral were obtained. The stress intensity factor is a measure of stress field at the crack tip whereas J-integral is the extent of energy release rate associated with crack growth. The above two parameters are related under linear material behavior.

\section{Results and discussion}

\subsection{Validation}

The stress intensity factors obtained from numerical modeling have been validated by analytical solutions. The mode I stress intensity factor $K_{1}$ for the SENT specimen was calculated as $[16,18,19]$

$$
K_{1}=\left\{0.265(1-a / w)^{4}+\frac{0.857+0.265 a / w}{(1-a / w)^{3 / 2}}\right\} \sigma \sqrt{\pi a}
$$

where $\sigma$ is the applied nominal stress in MPa, $a$ is the edge crack length in $\mathrm{mm}$, and $(a / w)$ is a dimensionless parameter which is the ratio of crack length to width. The unit of $K_{1}$ is $\mathrm{MPa} \vee \mathrm{mm}$. For adhesively bonded joint, Rose's model [19] was used as

$$
K_{p}=\frac{K_{1}}{1+\left(\frac{E_{p} t_{p}}{E t}\right)}\left[\frac{\left[\frac{t_{a}}{G_{a}}\left(\frac{E_{p} t_{p} E t}{E_{p} t_{p}+E t}\right)\right]^{1 / 2}}{a+\left[\frac{t_{a}}{G_{a}}\left(\frac{E_{p} t_{p} E t}{E_{p} t_{p}+E t}\right)\right]^{1 / 2}}\right]^{1 / 2}
$$

where $K_{p}$ is the mode I SIF of the single sided patch repair in $\mathrm{MPa} \sqrt{ } \mathrm{mm}, K_{1}$ is the mode I SIF of SENT specimen, $E$ is the modulus of elasticity, $G$ is the shear modulus and $t$ is the thickness in $\mathrm{mm}$. The $J$-integral was then obtained as

$$
J=\frac{1}{E^{\prime}}\left[K_{1}+K_{2}\right]+\frac{1}{2 G} K_{3}
$$

where $J$ is the energy release rate or $J$-integral in $\mathrm{N} / \mathrm{mm}$, $E^{\prime}=E$ for plane stress and $E^{\prime}=E /\left(1-v^{2}\right)$ for plane strain case, whereas $K_{1}, K_{2}$, and $K_{3}$ are the SIF in three directions.

The mode I SIF for the bare plate was $1616.77 \mathrm{MPa} \vee \mathrm{mm}$ obtained from Equation (1), compared to $1623.57 \mathrm{MPa} \sqrt{\mathrm{mm}}$ from our simulation. They agree very well with only $0.42 \%$ error. The mode II and III were negligible in this case.

For the single sided Kevlar-49/epoxy composite patch repaired plate, the J-integral value was $4.65 \mathrm{~N} / \mathrm{mm}$ from numerical results, which match well with analytical result of 4.56

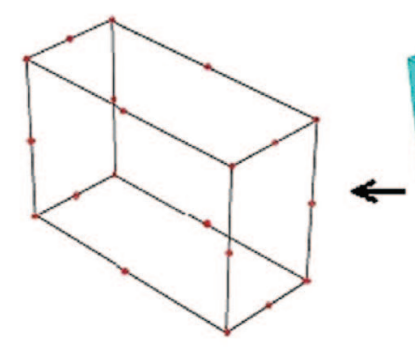

20 noded Hexahedral Element

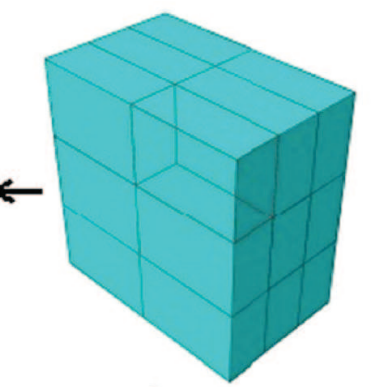

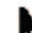

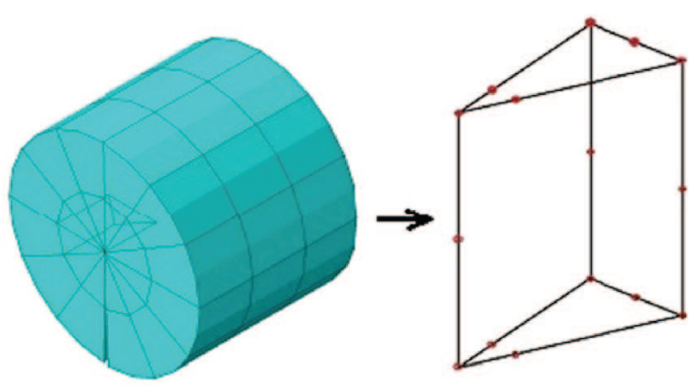

15 noded Quarter Point Element

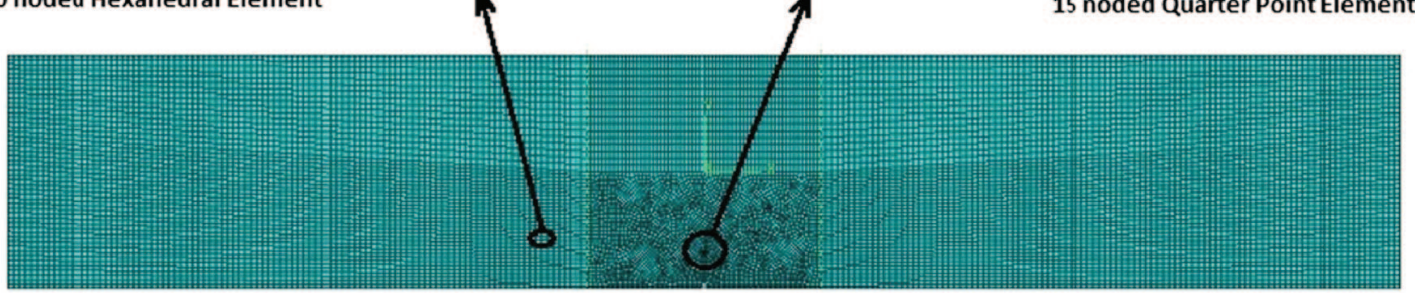

Figure 1. Finite element mesh of the plate where 20-noded elements are converted into 15-noded elements at the crack tip. 
Table 1. Material properties of cracked substrate, patches and adhesive [13, 15, 17].

\begin{tabular}{lcccc}
\hline Properties & Al 7075 T6 & Kevlar-49/epoxy & E-glass/epoxy & FM73 adhesive \\
\hline Longitudinal modulus $E_{1}(\mathrm{GPa})$ & 72 & 80 & 41 & 1.1 \\
Transverse in-plane modulus $E_{2}(\mathrm{GPa})$ & - & 5.5 & 12 & - \\
Transverse out of plane modulus $E_{3}(\mathrm{GPa})$ & - & 5.5 & 5.5 & - \\
In-plane shear modulus $G_{12}(\mathrm{GPa})$ & 28 & 2.2 & 5.5 & 0.44 \\
Out of plane shear modulus G $G_{13}(\mathrm{GPa})$ & - & 2.2 & 3.5 & - \\
Out of plane shear modulus G $G_{23}(\mathrm{GPa})$ & - & 1.8 & 0.28 & 0.44 \\
Major in-plane Poisson's ratio $v_{12}$ & -0.33 & 0.34 & 0.28 & - \\
Major out of plane Poisson's ratio $v_{13}$ & - & 0.4 & 0.5 & - \\
Major out of plane Poisson's ratio $v_{23}$ & - & & \\
\hline
\end{tabular}

$\mathrm{N} / \mathrm{mm}$. However, the obtained mode I SIF is $396.92 \mathrm{MPa} \sqrt{ } \mathrm{mm}$ from our computational model, which significantly differed from the analytical results of $603.83 \mathrm{MPa} \sqrt{\mathrm{mm}}$ from the Equation (2). This is due to the zero bending assumptions in the analytical formula, which transfer all the energy into the mode I SIF. In fact an out-of-plane bending is expected for a single sided repair and both mode I and mode II fracture shared the applied energy resources. Our 3-D simulation captured this bending effect which was not presented in the 2-D models. The mode II SIF was obtained as $369.38 \mathrm{MPa} \sqrt{\mathrm{mm}}_{\mathrm{m}}$ and was comparable to the mode I SIF whereas, mode III SIF was $-75.93 \mathrm{MPa} \sqrt{ } \mathrm{mm}$. This also indicates a 2D model usually overestimates the mode I SIF. This agrees with the experimental observations [20].

\subsection{Effect of patch repair}

The bonding between patch and cracked substrates will affect mechanical properties of the joint. The effectiveness of Kevlar-49/epoxy and e-glass/epoxy patches for repaired Al7075T6 specimen was evaluated in terms of stress distribution along the crack, SIF and CMOD. Figure 2 shows the stress concentrations at the crack tip is reduced with the composite patch repair. It is also clear that the Kevlar-49/epoxy composite patch repair is slightly better than the e-glass/epoxy patch in the stress reduction. The maximum Von Mises stress in the Kevlar-49/epoxy patch repaired plate is reduced by $85 \%$ from $5787 \mathrm{MPa}$ in the original cracked plate. The stress reduction is $80 \%$ for Al plate repaired by e-glass/epoxy patch.
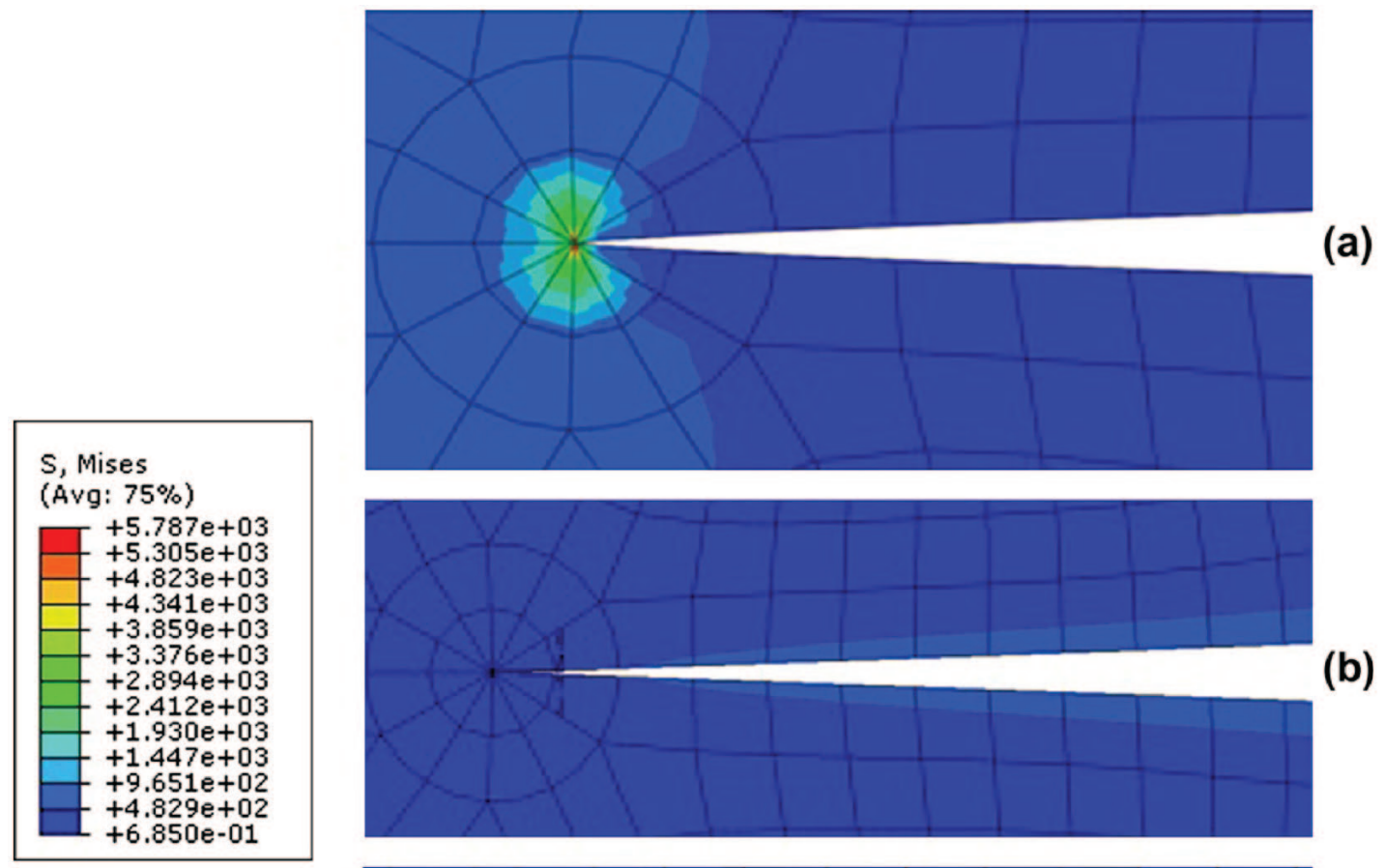

(a)

(b)
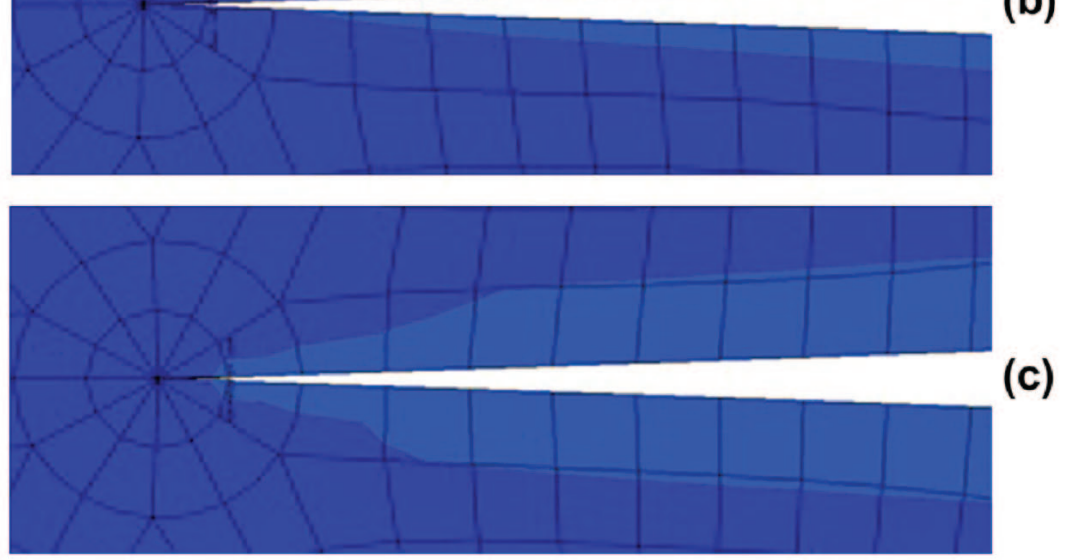

Figure 2. Stress map at the crack tip in (a) bareplate, (b) Kevlar-49/epoxy patch repaired plate, and (c) e-glass/epoxy patch repaired plate. 


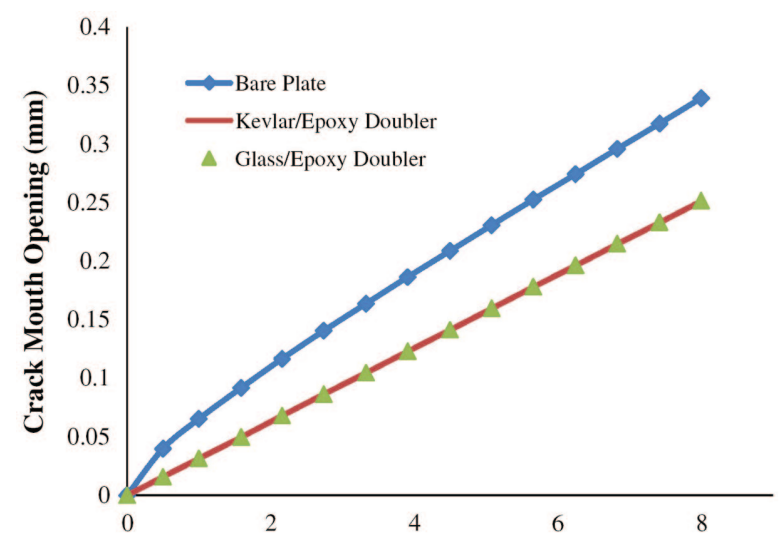

Figure 3. Crack profile for a plate repaired with Kevlar-49/epoxy and e-glass/epoxy patches.

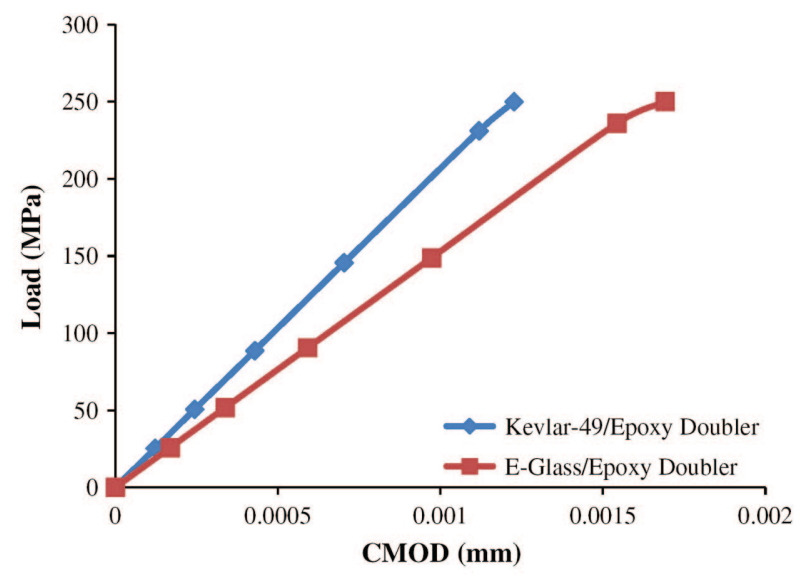

Figure 4. Effect of patch material on the crack behavior.

The stress intensity factor is the other measure of stress field at the crack tip, which is computed using interaction integral method [16]. The obtained mode I SIF for double sided repair is $165.3 \mathrm{MPa} \sqrt{\mathrm{mm}}$ and $218.81 \mathrm{MPa} \sqrt{\mathrm{mm}}$ for 1-ply Kevlar-49/epoxy and e-glass/epoxy respectively. Compared to the SIF of $1623.57 \mathrm{MPa} \sqrt{\mathrm{mm}}$ for the cracked bare plate, there is 7-10 times decrease in SIF. This could be explained by the higher rigidity in the loading direction of 1-ply Kevlar-49/epoxy material, which shares more than half of the load from the plate, thereby retarding the crack growth. This agrees with the speculation by Ouinas and Hebbar [21]. Moreover, reduction of SIF is also related to a smaller crack mouth opening displacement. Figure 3 shows the nonlinear crack profile with and without adhesive patches. Boned composite repair led to a reduction of CMOD at the edge of the plate by $79 \%$ with respect to the cracked Al plate. This implies a restored stiffness. At the same applied load, the CMOD of these two patch materials is less than half micrometer, as shown in Figure 4 . Kevlar-49/epoxy patched plate shows a slightly stiffer behavior than the e-glass/epoxy patched one, due to the larger mechanical strength of the patch material in the loading direction. This indicates the patch material is essential for the performance of the repair.

\subsection{Effect of crack length}

In general crack becomes unstable when its length exceeds certain limit [21]. To understand the role of crack length on the

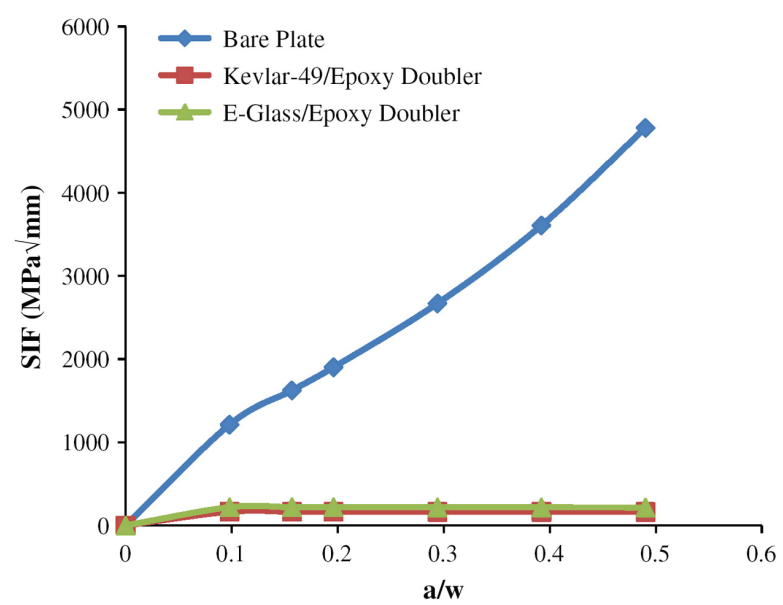

Figure 5. Effect of crack length on the SIF.

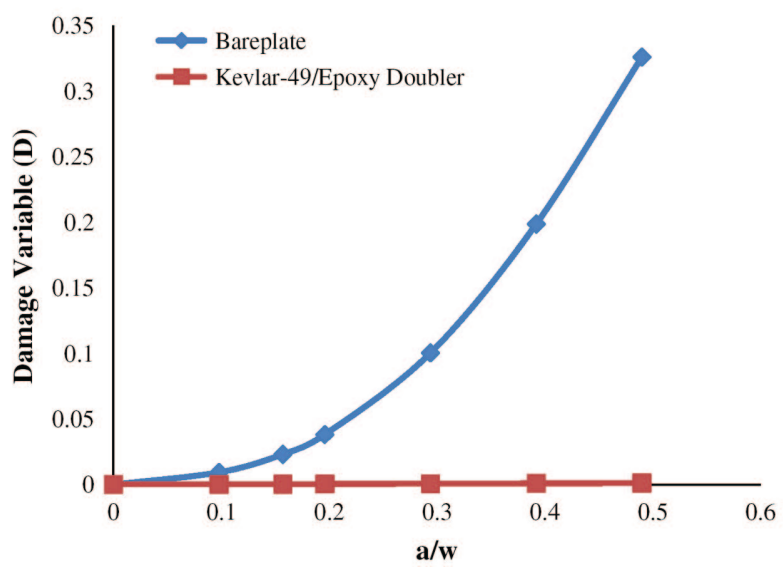

Figure 6. Damage factor with respect to crack length for plate.

stress field of the plate, various crack length as 9\%, 15\%, 19\%, $29 \%, 39 \%$, and $49 \%$ of the plate width $(w)$ were investigated. Figure 5 demonstrates a significant reduction of SIF as a result of repair using composite patches, especially for large cracks. It is obvious that a lager crack, under the same loading conditions, lead to a higher SIF, and a larger CMOD correspondingly. This is due to the crack, also referred to as damage in the continuum damage mechanics, reduced the deformation resistance of the plate to applied loads. Due to the load sharing capacity of the patch, the SIF, at the relative crack length $(a / w)$ of 0.49 , is reduced to $1 / 29$ for the Kevlar-49/epoxy repair and 1/22 for e-glass/epoxy one.

Damage of the joint is evaluated by monitoring stiffness and a damage variable $(D)$ was adopted as [22]

$$
D=1-\frac{E^{\prime}}{E}
$$

where $E, E^{\prime}$ refer to the original and current Young's Modulus, respectively. $D$ is set as zero when there is no crack present. The amount of damage of a structure depends on the relative change of the Young's modulus with the presence of cracks, as depicted in the Figure 6. It is clear that the stiffness of the bare plate is reduced by $32 \%$ with a half width edge crack i.e., $a / w=0.49$. After the cracked plate was repaired with Kevlar-49/epoxy doubler, the stiffness of the plate improved from the $39 \mathrm{GPa}$ to $88 \mathrm{GPa}$, and its damage $D$ can be neglected. This indicated a better loading capacity for a reinforced structure presuming a perfect adhesive bonding. 


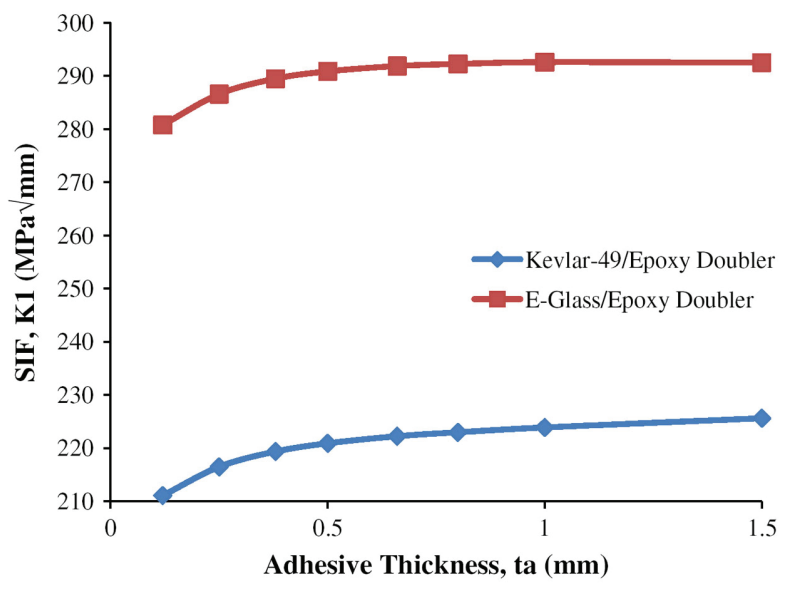

Table 2. Percentage of load sharing at various adhesive thicknesses.

\begin{tabular}{|c|c|c|c|c|c|c|}
\hline \multirow{2}{*}{$\begin{array}{l}\text { Adhesive } \\
\text { thickness } \\
\left(t_{a}\right)\end{array}$} & \multicolumn{3}{|c|}{ Kevlar-49/epoxy repair } & \multicolumn{3}{|c|}{ E-glass/epoxy repair } \\
\hline & $\begin{array}{c}\text { Plate } \\
(\%)\end{array}$ & $\begin{array}{c}\text { Patches } \\
(\%)\end{array}$ & $\begin{array}{l}\text { Adhesives } \\
(\%)\end{array}$ & $\begin{array}{r}\text { Plate } \\
(\%)\end{array}$ & $\begin{array}{c}\text { Patches } \\
(\%)\end{array}$ & $\begin{array}{c}\text { Adhesives } \\
(\%)\end{array}$ \\
\hline 0.12 & 50.196 & 49.705 & 0.138 & 66.617 & 33.198 & 0.184 \\
\hline 0.25 & 50.833 & 48.866 & 0.3 & 66.911 & 32.696 & 0.391 \\
\hline 0.38 & 50.980 & 48.559 & 0.460 & 67.009 & 32.388 & 0.601 \\
\hline 0.5 & 51.029 & 48.365 & 0.605 & 67.107 & 32.198 & 0.791 \\
\hline 0.8 & 51.078 & 47.968 & 0.953 & 66.911 & 31.842 & 1.246 \\
\hline 1 & 51.127 & 47.693 & 1.179 & 66.813 & 31.64 & 1.541 \\
\hline 1.5 & 51.225 & 47.05 & 1.724 & 66.519 & 31.227 & 2.252 \\
\hline
\end{tabular}

Figure 7. Influence of adhesive thickness on the SIF.

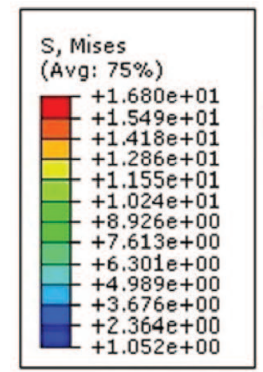

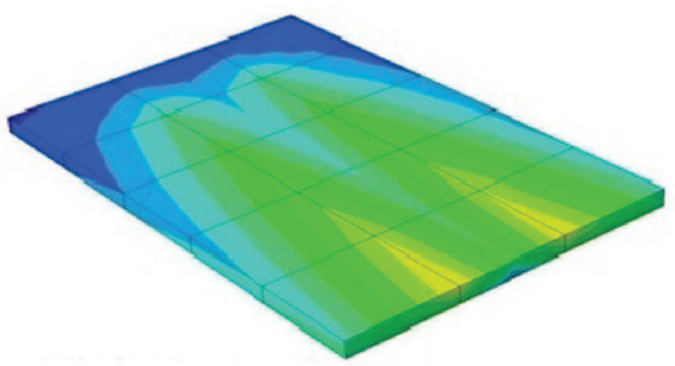

(a)

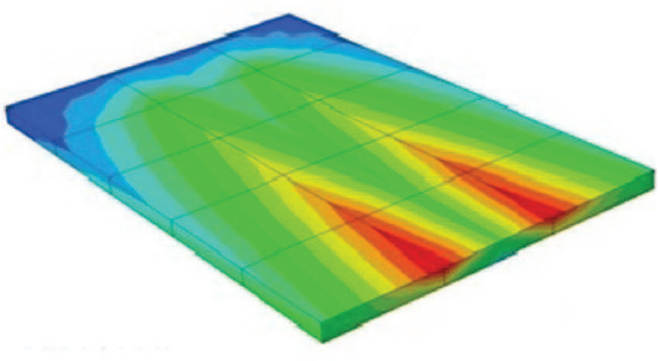

(b)

Figure 8. Stress map in the $0.25 \mathrm{~mm}$ thick adhesives at the crack location, using (a) Kevlar-49/epoxy patch, (b) e-glass/epoxy patch. The top surface is the adhesive-plate interface.

(a)

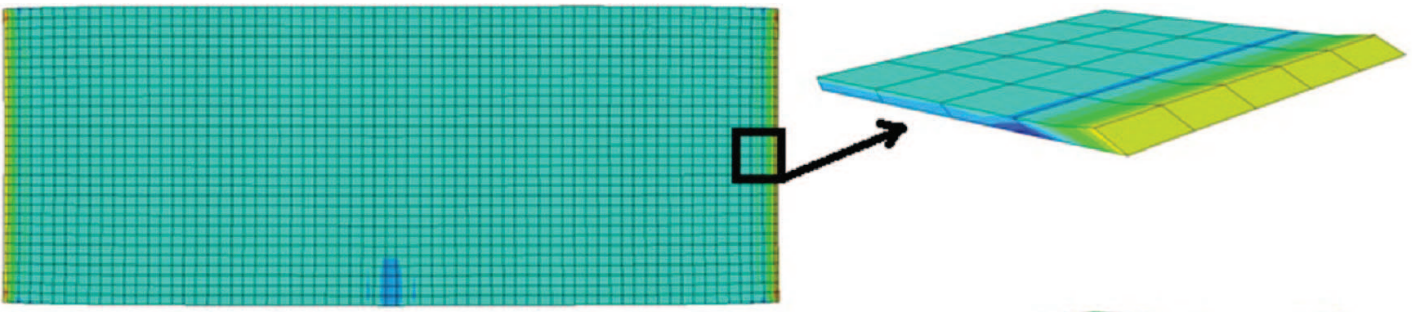

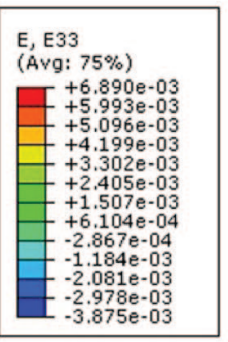

(b)

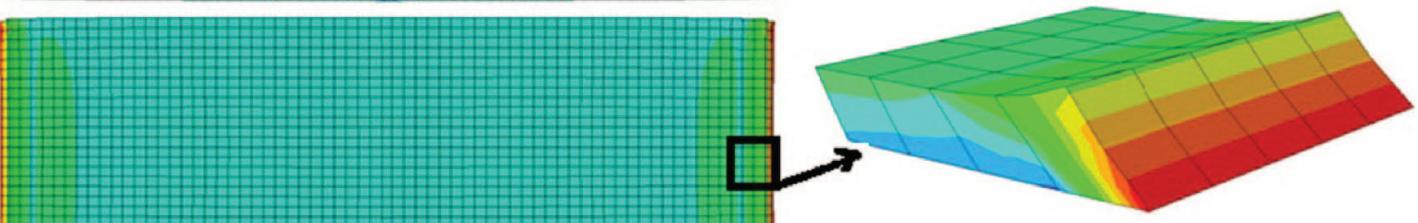

Figure 9. Strain distribution in the $0.25 \mathrm{~mm}$ (a) and $1.5 \mathrm{~mm}$ (b) thick adhesive for Kevlar-49/epoxy patch. A 50 times scaling is used for the zoom-in view of the peel strain distribution. The top surface is patch-adhesive interface.

\subsection{Effect of adhesive thickness}

Adhesive layer plays a vital role in transmitting load from the cracked plate to the composite patch. The geometrical features such as thickness can affect the mechanical strength at the adhesive-substrate interface. A thick adhesive layer results a large SIF regardless the patch material (Figure 7). Both Kevlar-49/epoxy and e-glass/epoxy patched repair demonstrated a sharp increase of SIF at the thickness around $0.25 \mathrm{~mm}$. But, as the adhesive become thicker, the SIF reaches a plateau. This may be due to the reduced load transmitting capacity of the thick adhesive. It is verified by our results (Table 2) that, after bonded composite repair, load shared by the patch reduced from $49.7 \%$ to $47.0 \%$ as the thickness of the adhesive increases from $0.12 \mathrm{~mm}$ to $1.5 \mathrm{~mm}$. The applied load shared by the patch, however, increased from $0.129 \%$ to $1.72 \%$. Since the adhesive layer is mainly served to transmit load, its increased share of the applied load is not desirable, which might cause adhesive delamination because of higher shear stress and relative weaker bonding [23].

Significant stresses resulted at the adhesive-substrate interface, especially where adhesive and substrate have significant 
different elastic modular, as shown in Figure 8. It is clear that a larger stress concentration of $16.8 \mathrm{MPa}$ exist at the e-glass/ epoxy patch-plate interface around crack region, compared to $11.09 \mathrm{MPa}$ at the Kevlar-49/epoxy-plate interface. Considering a Kevlar-49/epoxy patch repaired plate, a maximum inplane shear stress on the adhesive layer, located at the edge, is $0.29 \mathrm{MPa}$ for the $0.25 \mathrm{~mm}$ thickness, compared to $0.51 \mathrm{MPa}$ for the $1.5 \mathrm{~mm}$ thick adhesive. The peel force in the adhesive plane increased nearly 2-fold from the minimum load at the plate-adhesive interface to the maximum load at the patchadhesive interface. The maximum peel force in the adhesive is $255.9 \mathrm{~N}$ for the $0.25 \mathrm{~mm}$ thick adhesive, whereas, it is $564.5 \mathrm{~N}$ for the $1.5 \mathrm{~mm}$ thick one. This is mainly due to the relative large deformation in the adhesive edge, as demonstrated in the Figure 9. Our results demonstrate that a thinner adhesive layer is preferred, which lead to lower stress in the adhesive layer, higher percentage of load shared by patch material. However a strong bonding must satisfy minimum adhesive thickness. An optimum adhesive thickness suggested by Arenas et al. [23] is in the range of $0.25-0.4 \mathrm{~mm}$.

\section{Conclusions}

The aim of this paper was to use the finite element method to study the performance of bonded composite patch repair under uniaxial tension. The influence of material and geometrical properties of the adhesive and crack on the fracture parameters has been examined in terms of load transfer mechanism, shear stress distribution, SIF, CMOD and damage variable $D$ through three dimensional models. The conclusions are summarized as:

- Repairing a damaged structure with bonded composite patches on one side results in a mixed mode fracture behavior, which can be captured in 3D simulation. Our model is validated by analytical solutions.

- Composite repaired structure regains the service life by reducing the stress concentration and CMOD at the crack surface and reliving the SIF accordingly.

- The composite patch material affects the performance of the repair. Significant stresses resulted at the adhesivesubstrate interface, especially where adhesive and substrate have significant different elastic modular. There is $3.3 \%$ difference in the mode I SIF using a Kevlar-49/epoxy rather than e-glass/epoxy composite patch.

- Damage variable $D$ was used to assess the amount of damage in regard to relative stiffness of the material. A relative large crack lead to an unstable higher SIF and larger $D$, which could be reduced dramatically through bonded composite repair.

- The load carrying capacity is reinforced by composite patch. A thinner adhesive layer results in a higher percentage of load transmitted to the patch.

\section{Acknowledgments}

The supports of NASA Nebraska Space Grant and National Science Foundation under Grant No. 0811250 are gratefully acknowledged.

\section{References}

[1] A. A. Baker, Repair of cracked or defective metallic components with advanced fiber composites an overview of Australian work, Compos Struct 2 (2) (1984), pp. 153-181.

[2] L. J. Hart-Smith, The design of repairable advanced composite structures. Douglas Paper 7550, McDonnell, Douglas Aircraft Company; 1985.

[3] S. N. Atluri, Structural integrity and durability, Technical Science Press, Forsyth, Georgia, USA (1997).

[4] R. Jones and W. K. Chiu, Composite repairs in metallic components, Compos Struct 44 (1999), pp. 17-29.

[5] T. Ting, R. Jones, W. K. Chiu, I. H. Marshall, and J. M. Greer, Composite repairs to rib stiffened panels, Compos Struct 47 (1999), pp. 737-743.

[6] R. D. Henshel and K. G. Shaw, Crack tip elements are unnecessary, Int J Numer Methods Eng 9 (1975), pp. 495-509.

[7] R. S. Barsoum, On the use of isoparametric finite elements in linear fracture mechanics, Int J Numer Methods in Eng 10 (1) (1976), pp. 25-37.

[8] V. Murti, S. Valliappan, and I.K. Lee, Stress intensity factor using quarter point element, J Eng Mech 111 (2) (1984), pp. 203-217.

[9] T. V. R. S. Umamaheswar and R. Singh, Modeling of a patch repair to a thin cracked sheet, Eng Fract Mech 62 (1999), pp. 267-289.

[10] Ellyin Fennand, Ozah Folarin, and Xia Zihui, 3-D modelling of cyclically loaded composite patch repair of a cracked plate, Compos Struct 78 (2007), pp. 486-494.

[11] M. H. Dirikolu and A. Aktas, Analytical and finite element comparisons of stress intensity factors of composite materials, Compos Struct 50 (1) (2000), pp. 99-102.

[12] D. Ouinas, B. B. Bouiadjra, B. Achour, and N. Bender douche, Modeling of a cracked aluminum plate repaired with composite octagonal patch in mode I and mixed mode, Mater Des 30 (3) (2009), pp. 590-595.

[13] E. Ergun, S. Tasgetiren, and M. Topcu, Determination of SIF for patched crack in aluminum plates by the combined finite element and genetic algorithm approach, Fatigue Fract Eng Mater Struct 31 (11) (2008), pp. 929-936.

[14] W. Y. Lee and J. J. Lee, Successive 3d FE analysis technique for characterization of fatigue crack growth behavior in compositerepaired aluminum plate, Compos Struct 66 (2004), pp. 513-520.

[15] A. A. Baker, S. Dutton, and D. Kelly, Composite materials for aircraft structures (2nd ed.), American Institute of Aeronautics and Astronautics (2004).

[16] ABAQUS Version 6.9 online documentation, SIMULIA Inc.

[17] Q. Y. Wang and R. M. Pidaparti, Static characteristics and fatigue behavior of composite-repaired aluminum plates, Compos Struct 56 (2) (2002), pp. 151-155.

[18] H. Tada, P. C. Paris, and G. R. Irwin, The stress analysis of cracks handbook, ASME Press (2000).

[19] L. R. F. Rose, An application of the inclusion analogy for bonded reinforcements, Int J Solid Struct 17 (1981), pp. 827-838.

[20] Nicholas G. Tsouvalis and Lazaros S. Mirisiotis, Experimental investigation of the static behaviour of a hole drilled steel plate reinforced with a composite patch, Strain: Int J Appl Mech 44 (2) (2008), pp. 133-140.

[21] D. Ouinas and A. Hebbar, Full-width disbonding effect on the repaired cracks in structural panels with bonded composite patches, J Thermoplast Compos Mater 23 (4) (2009), pp. 401-412.

[22] A. Warhadpande, B. Jalalahmadi, T. Slack, and F. Sadeghi, A new finite element modeling approach for life scatter in tensile steel specimens, Int J Fatigue 32 (2010), pp. 685-697.

[23] J. M. Arenas, J. J. Narbon, and C. Alia, Optimum adhesive thickness in structural adhesive joints using statistical techniques based on weibull distribution, Int J Adhes Adhes 30 (3) (2010), pp. 160-165. 